\title{
Preliminary results of aerosol optical thickness from MIVIS data
}

\author{
C. Bassani ${ }^{1}$, R. M. Cavalli ${ }^{1}$ \& S. Pignatti ${ }^{2}$ \\ ${ }^{I}$ Institute for Atmospheric Pollution (IIA), \\ National Research Council (CNR), Italy \\ ${ }^{2}$ Institute of Methodologies for Environmental Analysis (IMAA), \\ National Research Council (CNR), Italy
}

\begin{abstract}
Aerosols are the principal atmospheric constituents which the radiative field in the atmospheric window of solar spectral domain depends on. This dependence have to be considered when the radiative quantities of the atmosphere are simulated for solving the radiative transfer equation written for at sensor signal. The most important parameter for these simulations is the aerosol optical thickness at wavelength of $\lambda=550 \mathrm{~nm}, \tau_{a}(\lambda=550 \mathrm{~nm})$, that is an input of the atmospheric radiative transfer codes used by the scientific community. The study carried out is based on the estimation of $\tau_{a}(\lambda=550 \mathrm{~nm})$ starting only from the MIVIS (Multispectral Infrared and Visible Imaging Spectrometer) remote sensing data. A minimization algorithm is applied to a quadratic cost function of the $\tau_{a}(\lambda=550 \mathrm{~nm})$ variable. In this paper are presented the preliminary results obtained from the MIVIS image processing in particulary pixels that satisfy both the conditions of lambertianity and spectral homogeneity of the surface.
\end{abstract}

Keywords: aerosol optical thickness, atmospheric radiative transfer, scattering, remote sensing.

\section{Introduction}

The aerosols are significant atmospheric constituents to estimate and predict direct component of climate forcing by scattering and absorption of solar and infrared radiation in the atmosphere [1]. Besides, Houghton et al. [1] showed that the aerosol mass and particle number concentrations are highly variable in space and time representing one of the largest uncertainties in climate change studies. In the 
last decades, the passive optical remote sensing data are observational support to estimate aerosol properties [2] since in atmospheric window the magnitude of atsensor signal depends on the direct radiative forcing exerted by the aerosols on the solar radiation [3-5]. The most sensitive variable of the radiative field model in the atmosphere is the aerosol optical thickness, $\tau_{a}(\lambda)$. This is the fundamental basis of atmospheric study in optical remote sensing: the analysis of the aerosol contribution by simulation of the atmospheric state, in scattering and absorption terms, is achieved by atmospheric radiative transfer codes.

For istance, Kaufman et al. [6] developed a technique for the aerosol retrieval over land from MODIS data based on the aerosol radiative effects noticeable in the visible spectral domain and negligible in the near infrared.

In this work, the preliminary results of the aerosol optical thickness retrieved by using remote sensing data of AA5000 MIVIS (Multispectral Infrared and Visible Imaging Spectrometer) sensor are presented for the first time. In order to greatly reduce the computational time, the least complicated approach described by Guanter et al. [7], has been used for this study. Initially, a cost function is created that measures the deviation between the remote sensing data observed by the sensor and simulated by the computer code for atmospheric radiative transfer, namely $6 \mathrm{~S}$ (Second Simulation of the Satellite Signal in the Solar Spectrum) [8]. The cost function is then minimized using the Powell algorithm described in [9]. The computed cost is dependent on the aerosol properties, mainly on optical thickness. Thus the minimum cost function provides the parameter set which fits the model most closely with the observed data.

\section{MIVIS data}

The Daedalus AA5000 MIVIS (Multispectral Infrared and Visible Imaging Spectrometer) is an airborne hyperspectral scanner [10] belonging to Italian National Research Council (CNR).

The MIVIS system is a whisk-broom scanner in which the light is collimated by the scan head and distributed by means of dichroic filters into four simultaneous recorder spectrometers operating in the visible, short-wave infrared and thermal spectral domain.

The sensor detects the downwelling radiation providing information on the earthatmosphere system according to the characteristics shown in table 1. MIVIS sensor has proven to be highly suitable to perform surface detection into natural [11] and urban [12] environments by using a carefully selected spectral bands of the instrument.

\section{Method}

In the atmospheric window of visible spectral domain, the attenuation of electromagnetic wave through the atmosphere is caused by several factors, primarily the scattering of aerosol. 
Table 1: MIVIS sensor technical details and spectrometer charasteristics.

\begin{tabular}{llcc}
\hline & Channels Number & 102 & \\
& Total Spectral Coverage & $0.43-12.7 \mu \mathrm{m}$ & \\
& Istantaneous Field Of View & $2.0 \mathrm{mrad}$ & \\
& Sample rate (angular step) & $1.64 \mathrm{mrad}$ & \\
& Total Scan Angle (FOV) & $71.059^{\circ}$ & \\
& Pixel per Scan-line & 755 & \\
\hline Spectrometer & Range & Channels & Bandwidth \\
\hline I - VIS & $0.43-0.83 \mu \mathrm{m}$ & 20 & $20 \mathrm{~nm}$ \\
II - NIR & $1.15-1.55 \mu \mathrm{m}$ & 8 & $50 \mathrm{~nm}$ \\
III - SWIR & $2.0-2.5 \mu \mathrm{m}$ & 64 & $8 \mathrm{~nm}$ \\
IV - TIR & $8.2-12.7 \mu \mathrm{m}$ & 10 & $450 \mathrm{~nm}$ \\
\hline
\end{tabular}

Thus, the radiative contribution of scattering process is not negligible on the atsensor radiance in the optical spectral range, this means that the sensor bands in the atmospheric window depends on the optical properties of the principal scatterers, the aerosols. The aerosol optical properties can be investigated from the at-sensor radiance by the inversion of the following radiative transfer equation written for the optical remote sensing data, [8]:

$$
\rho_{s i m}\left(\theta_{s}, \theta_{v}, \phi_{s}-\phi_{v}, z\right)=T_{g}\left(\theta_{s}, \theta_{v}, z\right)\left[\rho_{R+A}(z)+T^{\uparrow} T^{\downarrow} \frac{\rho_{s}}{1-S \rho_{s}}\right]
$$

In the equation $1, \rho_{\text {sim }}$ is the reflectance of the pixel observed by the sensor and obtained from simulation of radiative quantities; $\rho_{s}$ is the pixel reflectance measured at ground. The other terms are spectral radiative quantities, functions of solar zenith angle, $\theta_{s}$, view zenith angle, $\theta_{v}$, relative azimuth, $\phi_{r e l}=\phi_{s}-\phi_{v}$, and airborne altitude, $z \cdot T^{\downarrow}=e^{-\tau / \mu_{s}}+t_{d}\left(\theta_{s}\right)$ and $T^{\uparrow}=e^{-\tau / \mu_{v}}+t_{d}\left(\theta_{v}\right)$ are the total transmission, direct and diffuse component sum, of the atmosphere along downwelling, $\mu_{s}=\cos \left(\theta_{s}\right)$, and upwelling, $\mu_{v}=\cos \left(\theta_{v}\right)$, directions respectively, and where $\tau(z)$ is the aerosol optical thickness in the layer between the ground and the $z$ altitude. $T_{g}$ is the gaseous transmission; $\rho_{R+A}$ is the intrinsic reflectance of the molecular and aerosol layer; and $S$ is the spherical albedo of the atmosphere.

There are several codes to simulate the spectral radiative quantities presented in the equation 1, providing specific atmospheric parameters. In particular, the aerosol optical thickness at $550 \mathrm{~nm}$ wavelength, $\tau_{a}(\lambda=550 \mathrm{~nm})$, and the four pure aerosol types (dust-like, water soluble, oceanic and soot) are the underlying variable parameters to control the aerosol radiative contribution on the radiative quantities of the equation 1 by means of the radiative transfer code.

In this study, the $\tau_{a}(\lambda=550 \mathrm{~nm})$ and the aerosol types have been retrieved by an inversion method of the at-sensor radiance from the MIVIS bands, $L_{\text {meas }}^{\text {MIVIS }}$, 
that are inside the atmospheric window of visible spectral domain assuming that the reflectance of the MIVIS pixel used, $\rho_{s}$, is known. The algorithm is based on the existing approach developed by Guanter et al. [7] specifically for aerosol retrieval from remote sensing data of CHRIS (Compact High Resolution Imaging Spectrometer) sensor on-board of the PROBA (Project for On-Board Autonomy) satellite.

The inversion algorithm is performed by means of the cost function minimization designed on the at-sensor signal of a specific pixel measured by the MIVIS sensor and simulated by the 6S (Second Simulation of the Satellite Signal in the Solar Spectrum) atmospheric radiative transfer code described in [8]. The 6S satisfies the requirement of lower computational cost preserving the computational accuracy for aerosol scattering effects, [8].

In order to match measured $\left(L_{\text {meas }}^{\text {MIVIS }}\right)$ and simulated $\left(\rho_{\text {sim }}^{M I V I S}\right)$ MIVIS data, the at-sensor radiance has been expressed in terms of equivalent reflectance by the following equation:

$$
\rho_{\text {meas }}^{\text {MIVIS }}=\frac{\pi L_{\text {meas }}^{\text {MIVIS }}}{\mu_{s} E_{s}}
$$

where $E_{S}$ is the solar flux at the top of the atmosphere.

All the above-mentioned spectral quantities presented in the equation 1, namely $Q_{\lambda}$, and simulated by $6 \mathrm{~S}$ code (spectral sampling is $2.5 \mathrm{~nm}$ ), have been convolved in ith MIVIS band response filter, $f_{i}(\lambda)$, by:

$$
Q_{i}^{j}(x, y, z)=\frac{\int_{\lambda_{\min }}^{\lambda_{\max }} Q_{\lambda}^{j}(x, y, z) f^{j}(\lambda) d \lambda}{\int_{\lambda_{\min }}^{\lambda_{\max }} f(\lambda) d(\lambda)}
$$

where $(x, y, z)$ are pixel coordinates on which the inversion is applied. The $Q_{i}^{j}$ is the effective spectral value of $\mathrm{j}$ th simulated quantity referred to the ith MIVIS band. $\left[\lambda_{\min } ; \lambda_{\max }\right]$ is the spectral range of filter function of ith's MIVIS band.

Once the pixel reflectance is retrieved from MIVIS acquisition, $\rho_{\text {meas }}^{\text {MIVIS }}$, and $6 \mathrm{~S}$ simulation, $\rho_{\text {sim }}^{\text {MIVIS }}$, the aerosol properties are retrieved by the inversion of the equation 1 performing the minimization of the cost function described in [7]:

$$
\delta^{2}=\sum_{\lambda_{i}=1}^{20} \frac{1}{\lambda_{i}^{2}}\left[\rho_{\text {sim }}^{\text {MIVIS }}-\rho_{\text {meas }}^{\text {MIVIS }}\right]^{2}
$$

where $\lambda_{i}$ are the central wavelengths of the selected twenty MIVIS bands inside the atmospheric window of the visible spectral domain; the $\lambda_{i}^{-2}$ are the coefficients in order to weigh much more the MIVIS bands at the beginning of visible range where the aerosol scattering is higher and consequently the radiative contribution of aerosol on the at-sensor signal is considerable, after that the scattering decreases rapidly.

The inversion algorithm is performed by the Powell method [9] based on the minimization of cost function along each parameter space separately. Typically, 
design parameters that drive the inversion algorithm in the visible spectral domain and that are implemented in the $6 \mathrm{~S}$ database, are the aerosol optical thickness and the four aerosol types (dust-like, water soluble, oceanic and soot) presented in [13].

\section{Results}

The inversion algorithm, that is the minimization of the cost function expressed in the equation 4, has been applied to MIVIS data acquired in Venice lagoon $\left(45.4^{\circ} \mathrm{N}\right.$, $12.5^{\circ} \mathrm{E}$, Italy) the August 22th, 2006 at 11:41 UTC. The MIVIS scene, shown in the figure 1 , is a flat coastal region close to urban sites.

The selected study area, shown in the left of figure 2, includes pixels made up of concrete material only. The pixel reflectance, shown in the right of figure 2, satisfies the conditions of spectral homogeneity and reflectance isotropy. Both the conditions assure that the reference pixel reflectance, the $\rho_{s}$ of the equation 1 , is not composed by mixed materials and it is completely independent from the view and illumination angles (i.e., the bi-directional reflection function of the pixel is negligible). Besides, the clear sky at the MIVIS acquisition time was a particularly favorable radiative condition. The cloudless atmosphere implies that the radiative

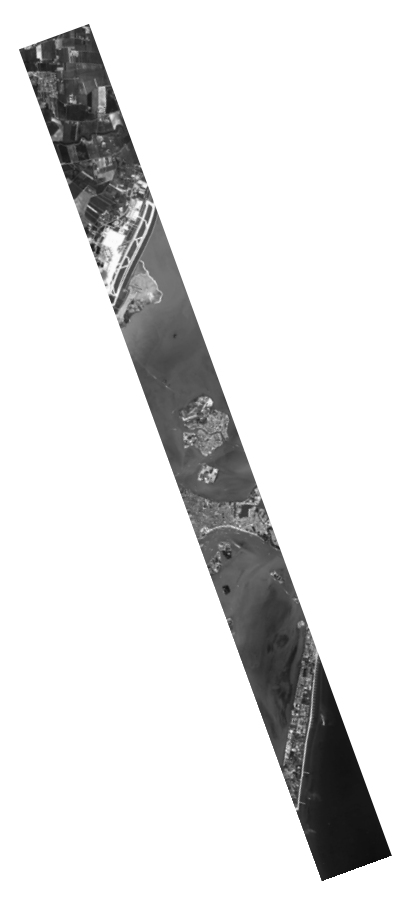

Figure 1: MIVIS image (oriented to the North) acquired in Venice lagoon $\left(45.4^{\circ} \mathrm{N}\right.$, $12.5^{\circ} \mathrm{E}$, Italy) the August 22th, 2006 at 11:41 UTC. The study area is the bright coastal region at the northwestern part of the image. 

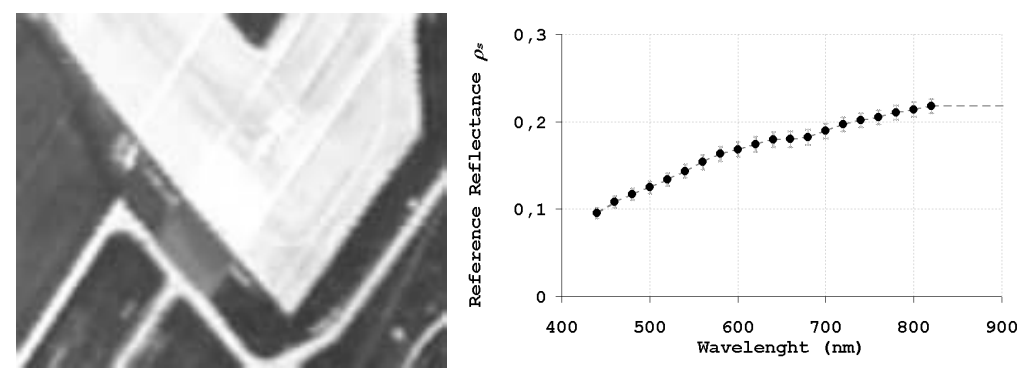

Figure 2: The study area selected on the runway of Venice airport in the coastal environment of the MIVIS image displayed in the figure 1. In the left side, zoom from the MIVIS image containing the selected square area composed by 112 pixel, being brighter than other ones; in the right side, the spectral reflectance of the area, made up of concrete material.

Table 2: Aerosol information retrieved from MIVIS data: aerosol optical thickness and the four aerosol types: dust-like, water soluble, oceanic and soot.

\begin{tabular}{ccccc}
\hline$\tau_{a}^{M}(\lambda=550 \mathrm{~nm})$ & $\%$ dust-like & $\%$ water soluble & $\%$ oceanic & $\%$ soot \\
\hline 0.142 & 19 & 32 & 38 & 11 \\
\hline
\end{tabular}

forcing effects on the at-sensor radiance depends principally on the aerosol scattering of solar radiation. Hence, the parameters space of the inversion algorithm can be considered to be composed by aerosol optical properties only.

As concern the aerosol information retrieved by the inversion algorithm applied to the selected area of the MIVIS scene, the values of aerosol optical thickness and the four pure aerosol types (dust-like, water soluble, oceanic and soot) are displayed in the table 2. Unlike the aerosol optical thickness, the final percentage of the four aerosol types are very close to the initialization values and to the values expected in Venice lagoon (urban and maritime aerosol). Therefrom, $\tau_{a}^{M}(\lambda=550 \mathrm{~nm})$ is the critical parameter to simulate the radiative effects of the aerosol scattering on the at-sensor radiance driving the inversion algorithm to the minimum of the cost function expressed by the equation 4 .

During the MIVIS acquisition time, a sun photometer in at-ground station measured the aerosol optical thickness at the $550 \mathrm{~nm}$ wavelength. The station operated in the framework of the AERONET network described by Holben et al. [14]. The location, time of measurements and the values of aerosol optical thickness at wavelength $550 \mathrm{~nm}$ for the station considered here, are given in the table 3 .

The aerosol optical thickness retrieved from MIVIS data, $\tau_{a}^{M}(\lambda=550 \mathrm{~nm})$, is compared with ground-based AERONET measurements, $\tau_{a}^{A}(\lambda=550 \mathrm{~nm})$. The correlation for $\tau_{a}^{M}(\lambda=550 \mathrm{~nm})$ against $\tau_{a}^{A}(\lambda=550 \mathrm{~nm})$ gives nearly a $1: 1$ relationship between retrieved from remote sensing and ground-based data, displayed in the table 2 and 3 respectively. 
Table 3: The AERONET site.

\begin{tabular}{lcccc}
\hline Location & Position & Julian Day & Time & $\tau_{a}^{A}(\lambda=550 \mathrm{~nm})$ \\
\hline Venice & long $=12.5$, lat $=45.3$ & 234.49 & $11: 46: 13$ & 0.138 \\
\hline
\end{tabular}

The method for evaluating the goodness of airborne result is the percent deviation from the at-ground measurement by the following equation:

$$
\Delta=\frac{\tau_{a}^{M}-\tau_{a}^{A}}{\left[\tau_{a}^{M}+\tau_{a}^{A}\right] / 2}
$$

The low value, $3 \%$, remarks the goodness of the results obtained from the first application of the inversion algorithm to the MIVIS data.

\section{Conclusions}

The first application of the inversion algorithm to retrieve aerosol optical thickness from MIVIS data has been presented in this work. The algorithm basically works by minimizing the cost function, expressed by equation 4 , in the space defined by the most sensitive parameters. The retrieval relies on the knowledge of the underlying surface reflectance of the pixel which the algorithm has to be applied. The algorithm uses the $6 \mathrm{~S}$ radiative transfer code to allow for lower computational cost maintaining the accuracy of the simulated data in the equation 1.

The preliminary results presented in this work highlight the potential of the optical MIVIS data in the assessment of aerosols optical properties related to the scattering of solar radiation. The algorithm has yielded information about the aerosol properties which helps to define, and providing understanding of, the atmospheric state during MIVIS airborne acquisition.

There are unsolved questions that have to be investigated further. In order to prove the robustness of the algorithm, increasing the MIVIS data where the method has to be applied on. The future plans also include to test the method in different aerosol content to analyse the performance of the inversion algorithm. Besides, the improvements of the algorithm are investigating about aerosol optical thickness without recourse to a priori information on the surface reflectance of the pixel observed, $\rho_{s}$ of the equation 1 .

\section{References}

[1] Houghton, J.T., Ding, Y., Griggs, D.J., Nouger, M., van der Linden, P.J., Dai, X., Maskell, K. \& Johnson, C.A., Climate Change 2001: The Scientific Basis. Cambridge University Press: Berlin and New York, pp. 11-13, 2001.

[2] Kaufman, Y.J., Theory and Applications of optical remote sensing, Wiley, chapter The atmospheric effect on remote sensing and its correction, 1989. 
[3] Charlson, R., Schwartz, S., Hales, J., Cess, R., Jr., J.C., Hansen, J. \& Hofmann, D., Climate forcing by anthropogenic aerosol. Science, 255, pp. 423430, 1992.

[4] Kaufman, Y.J., Tanré, D. \& Boucher, O., A satellite view of aerosols in the climate system. Nature, 419, pp. 215-223, 2002.

[5] Penner, J.E., Dong, X.Q. \& Chen, Y., Observational evidence of a change in radiative forcing due to the indirect aerosol effect. Nature, 427, pp. 231-234, 2004.

[6] Kaufman, Y.J., Wald, A.E., Remer, L.A., Gao, B.C., Li, R.R. \& Flynn, L., The MODIS 2.1-mum channel - correlation with visible reflectance for use in remote sensing of aerosol. IEEE Transactions on Geoscience and Remote Sensing, 35(5), pp. 1286-1298, 1997.

[7] Guanter, L., Alonso, L. \& Moreno, J., A method for the surface reflectance retrieval from PROBA/CHRIS data over land: application to ESA SPARC campaigns. IEEE Transactions on Geoscience and Remote Sensing, 43(12), pp. 2908-2917, 2005.

[8] Vermote, E., Tanré, D., Deuzé, J., Herman, M. \& Morcrette, J., Second simulation of the satellite signal in the solar spectrum: an overview. IEEE Transactions on Geoscience and Remote Sensing, 35(3), pp. 675-686, 1997.

[9] Press, W., Flannery, B., Teukolosky, S. \& Vetterling, W., Numerical Recipes, volume 1. Cambridge University Press, 2nd edition, 1986.

[10] Bianchi, R., Marino, C. \& Pignatti, S., Airborne hyperspectral remote sensing in Italy. EUROPTO series recent advances in remote sensing and hypespectral remote sensing, SPIE, volume 2318, pp. 29-37, 1994.

[11] Cavalli, R., Fusilli, L., Guidi, A., Marino, C., Pascucci, S., Pignatti, S., Casoni, L.V. \& Vinci, M., The natural areas of Rome province detected by airborne remotely sensed data. Annals of Geophysics, 49(1), pp. 187-199, 2006.

[12] Bassani, C., Cavalli, R., Cavalcante, F., Cuomo, V., Palombo, A., Pascucci, S. \& Pignatti, S., Deterioration status of asbestos-cement roofing sheets assessed by analyzing hypespectral data. Remote Sensing of Environment, 109, pp. 361-378, 2007.

[13] A preliminary cloudless standard atmosphere for radiation computation. Technical Report WCP-112, WMO/TD-NO.24, International Association for Meteorology and Atmospheric Physics, Geneva, Switzerland, 1986.

[14] Holben, B.N., Eck, T.F., Slutsker, I., Tanré, D., Buis, J.P., Vermote, E., Reagan, J.A., Kaufman, Y.J., Nakajima, T., Lavenu, F., Jankowiak, I. \& Smirnov, A., AERONET - a federate instrument network and data archive for aerosol characterization. Remote Sensing of Environment, 66, pp. 1-16, 1998. 